in her condition. On January 29th she had mild cholecystitis, which soon yielded to hexamine. There was a little pus on the right tonsil and slight rheumatism in the left shoulder, but nothing like it ised to be.

The chronic ill health and rheumatism of this patient was certainly very greatly improved pari passu with improvement in the tonsils.

CASE IV.

Miss P., aged 23. This patient had chronic appendicitis. Pus was cleared from her tonsils in seven treatments during two months without influencing the kinked appendix, which was excised as soon as it was convicted. After an untreated interval of three and a half months the tonsils were still clear of pus.

CaSe v.

Miss H., aged 25, was a keen athlete, but now too tired, even in the morning, for anything. She had tuberculous dactylitis as a child. There was offensive pus in both tonsils. I thought her tiredness was due to septic absorption, presumably from the tonsils. The pus contained few polymorphs; no pathogenic germs were recognized. On November 26th treatment by tonsil-suction were recognized. On November 26 th treatment by tonsil-suction
(iodoform, bismuth, and kerosene) was started. After much rest
and five treatments she was much better and could skate; there and five treatments she was much better and could skate; there was still slight pus in the right tonsil. On February 1st the
tonsils were clean. Ten days later there was a little pus, but her health was better than it had been for six months. On March 30 th she said she was " never tired"; there was very slight pus in the right tonsil.

Besides rest, this patient had no other treatment except (later) ultra-violet rays and arsenic, so that it looks as if her ill health had been due to septic tonsils.

\section{CAsE VI.}

A woman, aged 50, with seven months' constant asthma, which promptly vanished with one cleaning of the tonsils, and the pus almost cleared up in three treatments.

Two other severe and very chronic asthmatics (complicated) are not benefited (so far).

\section{Conclusions (Provisional).}

Although pus may be demonstrated by this method in many young adults in good health, yet it can hardly be doubted that, when they get older-to the fibrositis ageand less resistant, the infection will accumulate and conquer their resistance, and they will get rheumatism in some form.

I have been using tonsil-suction diagnostically for three years, and should estimate that in patients with fibrositis pus can thus be demonstrated in their tonsils in 90 to 95 per cent. of cases, acting as a focus of subinfection. The tonsils may look quite normal and yet contain pus. The ordinary method of expressing pus with a spatula may be far more painful; one patient said it was agonizing, whereas my method was merely unpleasant. It is a more searching method, and the pus can be seen (and smelt) by the patient. That is an important advantage. If there aro infected teeth or sinuses these should first be put right, as the tonsils may then clear themselves.

The method needs trying on a much larger scale and bacteriologically. I have been almost limited to private patients in a consulting practice; so that in these six patients alone has the treatment had a proper trial, except in one lady of 57 , where the issue was confused.

In the septic tonsils of adults, the risk of serious haemorrhage after tonsillectomy should be minimized by a preliminary course of tonsil cleaning by suction.

The method is at any rate quite harmless; two of $\mathrm{my}$ cases indicate the importance of cleaning the tonsils after a quinsy (or tonsillitis?) and seeing that they remain clean. Six to twelve treatments have usually cleared the tonsils of pus.

My plan is to make the intervals longer as soon as pus ceases to be found; but I cannot yet say whether a few treatments annually will be necessary to keep the tonsils freo from pus. Perhaps better pastes will be more effective. Evidently tonsillectomy is the best cure when possible and safe; but in adults it is practically a major operation, and in many patients it is out of the question. Painting tonsils containing deep pus is evidently fatuous. Hence an alternative is most desirable, and seems to be provided by this method, which is available to the general practitioner.

The glass funnels are much more subtle than they looklike golf clubs-and I have had to stand long over the very skilful glass-blower to get them right. Messrs. Reynolds and Branson, Leeds, are the makers.

\section{INTRATRACHEAL INHALATION AND INSUFFLA- TION OF CHLOROFORM BY MEANS OF A FLEXIBLE METAL CATHETER.}

\author{
BY
}

W. DAKIN MART, B.A.Cantab., M.R.C.S., L.R.C.P., SENIOR ANAESTHETIST AND LECTURER ON ANAESTHETICS, THE ROYAL INFIRMARY, SHEFFIELD.

Somr fiftecn years ago I wrote a paper on the intratracheal insufflation of chloroform by means of a gum-elastic catheter. This catheter did not last long, and had to be continually replaced. For some time now, however, $\mathrm{Mr}$. W. S. Kerr, honorary surgeon to the nose, ear, and throat department of the Royal Infirmary, Sheffield, and I have used, instead of the gum-elastic catheter, one made for the most part of flexible metal, and this has given every satisfaction to both the surgeon and the anaesthetist.

The method of administration differs somewhat from the old procedure. The instruments used include a flexiblo metal catheter, an adapter, a Junker's apparatus, completo with tubes and bellows, and an anaesthetic mask for induction.

The flexible metal catheter is made by Mayer and Phelps in two sizes, No. 12 and No. 16; it is rigid at either end for about two inches, the remaining part being flexible. (See figure.) The internal non-flexible part has an opening at the side, in addition to the end opening. The external non-flexible part, which during action is wholly outside the mouth, is a copy of the internal, except that the external end is somewhat funnel-shaped. The openings at the side are of the same lumen as the catheter, or possibly slightly larger. A blunt metal stilette is provided, the length of which is less than the length of the catheter; this provides rigidity to the catheter during introduction.

The metal adapter (see figure) is made to fit into the funnel-shaped end of the catheter by one end, whilst the other end is attached to the rubber exit tube of the Junker apparatus. The lumen of the adapter is either No. 12 or No. 16 catheter size, according to which size is in use. Ono Junker's apparatus has all its tubes No. 12 catheter size, and the other all its tubes No. 16 catheter size, for employment with the appropriato size of catheter.

The following method is adopted to induce and maintain anaesthesia.

Preliminary medication is by means of morphine and atropine, which should be injected at least half an hour before induction is commenced. Anaesthesia is induced by means of chloroform dropped on to a mask; this should be fairly deep, because otherwise the patient may come round during the introduction of the catheter into the trachea. When the patient is fully anaesthetized the catheter is at once introduced into the trachea with the aid of a bronchoscope, the stilette being within the catheter.

The catheter having been introduced through the vocal cords, the stilette is at once withdrawn and the catheter attached, by means of the adapter, to the rubber exit tube of the Junker apparatus. There may be some coughing at this stage if the patient has not been sufficiently anaesthetized, but this can soon be remedied by placing the finger over the hole in the rigid portion of the catheter outside the mouth and pumping chloroform vapour into the lungs by means of the bellows of the Junker apparatus. I usually at this stage give three pumps with the bellows while my finger is over the hole, and then remove my finger so that the patient may have a breath of air, and repeat this procedure until the patient is again completely anaesthetized. I do not think there is any danger, at this stage, to the alveoli from excess pressure by this pumping, as there is plenty of room outside the catheter in the trachea to act as a safety valve.

The surgeon now completely plugs the throat around the 
catheter with sponges, so that the alveoli now get the full effect of any excess pressure from the bellows, which must be used, therefore, very lightly. In practice it will be found that as soon as the sponges have been placed in position the pumping of chloroform vapour into the lungs is no longer necessary, as the patient will draw chloroform vapour through the Junker apparatus on inspiration, when the finger is placed over the external hole in the catheter. $I$ therefore remove the bellows from the Junker apparatus, and the patient inspires chloroform or air as desired by the anaesthetist. The anaesthetist must never forget that he now has that which the patient breathes absolutely under his control, just as is the case in the administration of nitrous oxide and oxygen. He has therefore to find out the ratio of air to chloroform vapour required by each patient to keep them in a satisfactory stage of maintenance.

I usually start, when the stage of maintenance has been reached, with three inspirations of chloroform vapour inhaled by the patient through the Junker apparatus to one inspiration of air inhaled through the side opening in the catheter outside the mouth; in other words, the finger is placed over the side opening in the catheter while the patient takes three inspirations of chloroform vapour, and the finger is taken away from the opening whilst the patient takes one inspiration of air. What actually happens when the finger is taken away from the opening, after the three inspirations of chloroform vapour, is that an expiration is the immediate result, followed by an inspiration of air, then another expiration through the opening, and then the finger is again placed over it to permit the three inspirations of chloroform vapour, and so on. This $I$ find is the average ratio of chloroform to air which suffices to keep a patient in the stage of maintenance and in a good condition. Some patients, however, require more air to keep their blood a good colour than others, and, on the other hand, there are some who require a bigger proportion of chloroform vapour to air to keep them fully anaesthetized. The deeper the anaesthesia the lighter the breathing, and the lighter the anaesthesia the deeper the breathing during the stage of maintenance.

The anaesthetist should keep a constant watch on his Junker bottle, in order that he may note the force with which the chloroform vapour is drawn through. This is a most excellent index of the force and depth of the patient's inspirations. Should the bubbling of vapour through the Junker become light I invariably take this as an indication that the patient requires more air, and accordingly see that he has it.

The advantages of this method are:

1. The maintenance of a perfectly clear airway.

2. The prevention of blood entering the air passages owing to the complete plugging of the throat around the catheter.

3. The absolute control of the amount of anaesthetic inhaled by the patient.

4. The patient inlales at each inspiration, by his own cfforts, the amount of anaesthetic or air which the anaesthetist thinks he requires. Pumping by means of the Junker bellows is dispensed with.

This variety of anaesthesia is undoubtedly the best method to adopt in all operations on the upper jaw or nose, and I have not the slightest doubt that anaesthetists who use it will be pleased with the result.

Mr. W. S. Kerr, at whose suggestion the flexible metal catheter was made, and at whose request $I$ have written this paper, is very well satisfied with the results from the surgeon's point of view. My thanks are due to him for suggestions given to me in compiling this paper, and also to Messrs. Mayer and Phelps for making the catheter and adapter.

\section{Attemoranda: MEDICAL, SURGICAL, OBSTETRICAL.}

\section{CONGENITAL HEART-BLOCK.}

THE occurrence of two cases of congenital heart-block in one family is so unusual as to deserve being placed on record.

A married woman, aged 21, was delivered of her first child, a female, in 1922. This child has been under $m y$ observation since birth; her ventricular heart rate has varied from 40 to 60 beats a minute, and the pulse has always been regular in force and rhythm. During the first few years of life the child lacked energy, and was cyanosed at times, particularly in cold weather she walked slowly, refused to be hurried, never ran, and was quite content to lie still for long periods. This state of affairs quite content to gradually disappeared, and now, at the age of 6 , she appears to the casual observer as an ordinary healthy child, able to run about
and up hills with no more distress than the average child. There is now no cyanosis. The ventricular heart beat when last noted was 42 , and regular in force and rhythm. The cardiac dullness is increased to the left, and the apex beat is in the fifth space, one inch outside the mid-clavicular line. On walking up and down stairs three times the ventricular beat remained regular and did not alter; there was no apparent increase in the cardiac dullness, and the only effect of this exertion was a slight temporary increase and the respiratory rate. The systolic blood pressure is now in the respiratory rate. The systolic blood pressure is now pressure in this child owing to the small size of the arteries at her age.

The heart has apparently accommodated for its slow beat by an increase in size and force of beat sufficient for the present for all ordinary purposes, but it would appear wise

by avoiding as far as possible undue stress.

Subsequent to the birth of this child two normal boys were born, each at an interval of two years. In March, when examining the mother, who was eight months pregnant, I noted the foetal heart rate was 39 ; at subsequent examinations the rate varied between 40 and 60 . A female infant was born normally on March 17th. Immediately after birth the pulsation of the cord was 63 and slightly irregular, with occasional forcible beats; this soon steadied to a regular even rate of 48 . The baby cried strongly; its weight at birth was $7 \mathrm{lb}$. There are at present no murmurs, no evident enlargement of the heart, and no cyanosis, but the mother states that there were frequent attacks of blueness during the first fortnight. At the age of 1 month the baby is doing the first fortnight. At the age of the ventricular heart rate.

well and appears normal, except for the ventricular heart rate.
Mikulicz's disease-a chronic swelling of the parotid glands with occasional severe attacks of swelling of all the salivary glands, for
no particular reason, but so severe as to need morphine for the no particular reason, but so severe as to need morphine for the
relief of the pain. She is slightly deaf as the result of middle-ear disease in childhood, but is otherwise healthy. The father is normal, except for the loss of a leg, the result of war wounds. There is no history or evidence of any venereal disease, and no history of heart trouble among the relations.

Apparently the development of congenital heart-block, or perhaps the failure to develop normal conductivity, is developmental in origin, and it is pure coincidence that two cases of such a rare disease as congenital heart-block have occurred in the same family.

Tunbridge Wells

$$
\text { R. D. Aylward, M.R.C.S., L.R.C.P. }
$$

\section{A CASE OF SOMATIC TAENIASIS.}

Dr. Robert Hutchison, on March 3rd, 1928 (p. 335), warned us against diagnosing rarities, but they do sometimes occur, as is shown by the following report of a case of generalized tapeworm infection.

A strong young man became an invalid, his first complaint being severe headache. Malaria was thought of and eliminated, but early pernicious anaemia was considered possible The patient then said that his fingers and thumbs tingled, and pains ran down his legs; he staggered when he walked. As there was nothing to account for his symptoms he was thought to be malingering, but he then became really ill. His left leg swelled and his temperature rose, but after a few days he recovered. $\mathrm{He}$ commenced work, but shortly afterwards had a fit. These fits recurred and were thought to be hysterical, but I doubted this etiology. His speech became hesitating. He looked at times an invalid, but ai other times I saw him walking briskly and normally. He then brought to my notice some lumps under his skin, which were tender and about the size of a large pea. I thought that these lumps might clear up the mystery of his disease. I was asked to certify him as insane, but at my examination I discovered he had double vision, and so I decided that the case was phrsical, not mental, and this despite the fact that he had auditory hallucinations. At length a lump was excised, and had auditory The pathologist reported that it was a cyst containing larval worms, probably the cysticercus stage of pork tapeworms.

Thus the mystery was solved; it was a case of visceral costodes. The rarity of this condition is mentioned in the article on diseases caused by cestodes in Osler's Textbook 